\title{
The Mediating Role of Knowledge Creation on the Market Sensing- Innovation Nexus
}

\author{
Okechukwu Lawrence Emeagwali \\ Faculty of Business Management, Girne American University, Cyprus \\ E-mail: lawrenceemeagwali@gau.edu.tr
}

Received: July 6, 2021 Accepted: August 10, $2021 \quad$ Published: August 11, 2021

doi:10.5296/ijssr.v9i2.18929 URL: https://doi.org/10.5296/ijssr.v9i2.18929

\begin{abstract}
This study examined the influential role of knowledge creation in facilitating the effect of market-sensing on innovation. It specifically examines this phenomenon among small and medium scale enterprises (SMEs) in Nigeria. The study hypothesized that market sensing will exogenously have a significant and positive effect on knowledge creation, which will in turn have a positive effect on innovation. Data was collected from strategic managers from the top management teams of 310 small and medium scale enterprises randomly selected from the country's six geopolitical zones. Using covariance based structural equation modeling (SEM) carried out via version 23 of IBM's AMOS software. Findings confirmed all four hypotheses specifically demonstrating that market sensing positively impacted knowledge creation and innovation, while knowledge creation was both found to have a positive effect on innovation and to also significantly mediate the effect of market-sensing on innovation. The study then discusses the implication of the findings for both literature and practice, while recommending areas for future research.
\end{abstract}

Keywords: strategy, business strategy, knowledge creation, market sensing, SMEs 


\section{Introduction}

The ubiquity diversity of Small and medium-sized enterprises (SMEs) is remarkable. This is because even in situations where a common definition is determined, especially at the national level, they still do come in different shapes and sizes. This is due to the fact that the word SME refers to a wide range of enterprises and organizations, including everything from local dressmakers, eateries, and garage shops to software development start-ups (Hallber, 2000). SMEs have a wide range of abilities and complexity, and they can operate in a variety of social and market environments. They could be creative, dynamic, and focused on expansion, or they could be plain, traditional enterprises comfortable with their current size. SMEs are defined differently depending on the country; for example, the value of the firm's asset, sales, or the total number of employees hired (Ayyagari et al., 2007; Perrewe et al., 2002). As a result, the economic significance of SMEs in these countries, and around the world, is enormous. In order to increase employment, improve economic development, and reduce poverty, the World Bank has recognized the importance of SMEs (Ayyagari et al., 2006). The ability to detect the industry and respond to changes in industry rivals' moves, technological advancements, latent and open consumer demands, and leveraging the capabilities and assets of various stakeholder groups will aid small businesses in developing novel products or incorporating new attributes or characteristics into existing ones to satisfy the expectations of existing and new customers, as well as ensuring stewardship. Innovation has been linked to the ability to feel the marketplace (Ardyan, 2016), predict business environment adjustments (Fang et al., 2014), as well as process and manage knowledge in a number of earlier studies (Quintane et al., 2011).According to Soek-Borowska (2017), SMEs take the process of knowledge production very seriously, even if they don't take other parts of knowledge management very seriously. She stated that SMEs are able to achieve what larger organizations are unable to do, which is to establish an environment that encourages the creation of knowledge through collaborative efforts, face-to-face communication, and a cult of ownership. Furthermore, SMEs continue to confront fierce competition from all corners of the globe mostly as result of globalization. Because previous research has not examined the impact of market-sensing capability on knowledge creation in the sphere of product innovation on innovation, our research study aims to compare the effect of market-sensing abilities on knowledge creation and process and product innovation in SMEs, as well as the mediating role of knowledge creation. This work has added to the previous conflicting findings both theoretically and practically, as well as providing important managerial insights.

\section{Review of Literature}

\subsection{Market Sensing and Knowledge Creation}

Various organizational competencies have been identified as critical factors in a firm's quest for competitive advantage by a growing body of research (Day, 1994). Market Sensing is a technique for creating a company that is adept at studying, perceiving, and reacting to market dynamics. Jaworski and Kohli (1993) describe market sensing as "a broad generation of market intelligence by an organization relating to changing needs of customers, dissemination 
of this knowledge across the organization's functional units, and the organization's responsiveness/reaction to the market" in relation to knowledge creation. Knowledge production among organizational units allows for shared learning and cross collaboration, both of which help to foster the creation of new knowledge (Tsai, 2001). Learning is the critical method for forming and preserving information and practical knowledge inside an organization. Knowledge production, according to Nonaka et al. (2006), is the process of making knowledge available, amplifying it, and developing it in the context of a firm's knowledge system. The knowledge system records organizational learning (Nonaka et al., 2006). Such sensing knowledge permits more precise forecasting of the market environment, the firm's commercial power to influence its surroundings, and the accuracy of the firm's overall planned actions (Cohen \& Levinthal, 1990). The consequent knowledge obsolescence is caused by the acceleration and turbulence of environmental change (Vorhies, 1998). Within an organization, departments can share ideas and benefit from fresh information obtained from other units. The knowledge-based view of the company (KBV) hypothesis, as previously mentioned, provides for the entrenchment of knowledge in an organization's market sensing capability. As a result, market sensing ability can generate a lot of market knowledge, which is important for any active capability (Teece, 2007;2012). As a result, a firm's market sensing capabilities have a favorable impact on the development of knowledge.

$\mathbf{H}_{1}$ : The ability to sense the market has a substantial impact on SMEs' knowledge creation.

\subsection{Market-sensing and Innovation}

A firm's competence is defined by its ability to do tasks on a regular basis that are related, either indirectly or directly, to the firm's ability to produce value by converting inputs into outputs (Grant, 1996a). Most firms develop diverse skills that enable them to carry out particular operations necessary to advertise their goods or services throughout the value chain. Market-driven businesses use product enhancement as a core competency strategy (Lukas \& Ferrell, 2000). Enterprises that generate differentiated, superior products and have general developmental qualities can outperform firms that are less market-oriented (Vorhies, 1998). A company's willingness to embrace or generate novel, relevant, and unique products or services is referred to as innovativeness. It is also a firm's willingness to adapt and absorb the latest technology and market trends, as well as a firm's openness to embracing new concepts, products, and methods (Rakthin et al., 2016). Openness to changing market needs frequently results in the introduction of new products and services to meet the changing wants and expectations of customers (Jaworski \& Kohli, 1993; Andreou et al., 2017). As a result, improving marketing skills will improve an organization's ability to respond to difficulties and opportunities produced by environmental instability (Vorhies, 1998). Customer and competition preferences, according to Lukas and Ferrell (2000), have a variety of effects on the creation of a new product. The necessity for external market knowledge, such as a sense of client wishes, demands, and service procedures, has been cited as critical for new innovation (McKelvie et al., 2018). According to Teece (2007), the probability that innovation would be profitable in the market is one of the most dependable conclusions from experimental investigations. The necessity for new products and external market research is exacerbated by the methodical nature of technology innovation. Furthermore, market sensing 
abilities ensures that product quality is improved, that post-sale services are provided in order to retain existing customers, and that the firm is able to achieve greater marketing and financial success (Rakthin et al., 2016). Based on the foregoing, it is hypothesized that a firm's market sensing talent has a favorable impact on procedures and a new product.

$\mathbf{H}_{2}$ : The ability to sense the market has a substantial impact on SMEs' process and product innovation.

\subsection{Knowledge Creation and Innovation}

Knowledge creation studies are primarily used to demonstrate the development processes and impacts of various types of knowledge in an organization (Ben-Menahem et al., 2016). Internal research on knowledge creation suggests that there are two ways to understand the knowledge formation process in companies. The first is an inside perspective, and the second is an ecological perspective (Peschl \& Fundneider, 2014). New knowledge begins with cognitive metaphors that connect competing models, according to proponents of the internal view, and is generated when existing knowledge is distributed and transmitted inside an organization's staffs (Nonaka \& von Krogh, 2009). Environmental differences have been shown to have an impact on a company's strategy and organizational structure (Miller \& Shamsie, 1996). Quintane et al. (2011) argue that the knowledge production process allows for the collaboration and dedication of specialized expertise from multiple areas of operation. As a result, redundancy can be eliminated, process efficiency improved, and new product expansion increased. However, according to Sankowska (2013), organizations that adapt strategic knowledge formation have a greater inclination to achieve originality and process advancements. As a result of the link between knowledge formation and innovation, it can be concluded that knowledge formation has a significant impact on processing and product innovation in an organization.

$\mathbf{H}_{3}$ : SMEs' process and product innovation are influenced by knowledge generation.

\subsection{The Mediating Role of Knowledge Creation}

Market demands identification allows enterprises to recognize those needs and desires, and if demand changes, the organization can respond quickly and address those needs by presenting relevant offerings or providing service. That is, an organization's ability to understand a market will impact how it responds to a customer's requirements and wishes. In light of the preceding assumption, the more inventive a company is, the faster it may adapt its products to provide sufficient advantages to clients; consequently, this applies to companies that are creative and productive when it comes to offering new products and services (Quintane, 2011). Market-sensing abilities have been assessed using a variety of methodologies, including process and product innovation (Cladea, 2014). According to Day (1994), marketing approaches are usually business specific, therefore developing critical marketing skills is a way for individuals to combine their knowledge and competencies with the available resources. Valued competencies, such as marketing talents, are difficult to mimic, replace, or transmit inside competitors; as a result, these capabilities form the foundation for a viable competitive advantage (Grant, 1996b; Möller \& Anttila, 1987). As a result, a company 
is urged to build a strong competitive edge by giving a natural greater offering to clients that goes beyond conventional market operation. Knowledge formulation, according to research, provides vital raw material for innovation in the form of distinct information, new understandings, a fresh perspective, greater creativity, collaboration, third-party collaborations, and continuous learning (Quintane et al., 2011; Sankowska, 2013). If a company lacks these characteristics, it will stymie any attempt at innovation. This is in line with Galunic and Rodan (1998), who claim that context-specific knowledge is unlikely to be consumed immediately. Second, market sensing-derived external knowledge is better utilized when paired with the firm's current expertise. When current knowledge from within the system is combined with well-internalized knowledge from outside sources, businesses can innovate more effectively (Shu et al., 2012). As a result, it is hypothesized that the process of knowledge generation mediates market-sensing ability as well as process and product innovation in a corporation.

$\mathbf{H}_{4}$ : Knowledge creation has a substantial mediating effect on SMEs' market-sensing capability, as well as their process and product innovation.

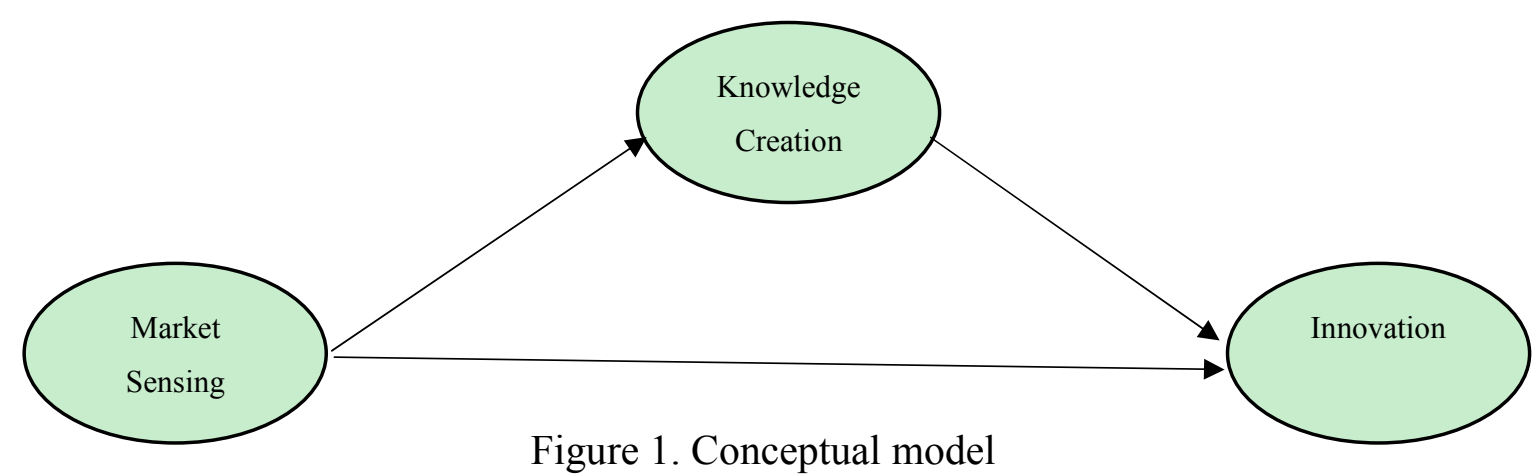

\section{Methodology}

\subsection{Research Design and Sampling Technique}

AA survey of all managers of service and manufacturing SMEs was undertaken in Nigeria. To eliminate selection bias, we used the survey monkey sampling size calculator to figure out how many SMEs we'd need for this research. Based on the results, 310 services and manufacturing SMEs were found to be suitable for the study, with a Margin of Error of 5\% and a Confidence Level of $95 \%$ and a Population Size of 41.5 million registered SMEs operating in

Nigeria (https://smedan.gov.ng/41-5m-msmes-registered-in-2017-nbs-smedan-national-survey/)

Following that, data acquired through surveys was dispersed using simple Random sampling procedures, which included approaches for decreasing or eliminating errors in survey responses generated. 


\subsection{Construct Measurement}

The administered survey is divided into two sections: the first contains questions for the researcher variables, which are divided into four sub-sections, and the second contains demographic information on the participating companies. For market sensing capabilities, research constructs and items were recorded, and a five-item scale was used (Cohen, \& Levinthal, 1990). Here, 1 denotes (strongly disagree) and 5 denotes (strongly agree) (strongly agree). Nonaka et al. (1994) validated ten items on a 5-point rating scale $(1=$ strongly disagree to $5=$ strongly agree) to reflect the knowledge generation process. Kerlavaj et al. used 11 different things to model and capture product and process innovation (2010). The questions were graded on a 5-point scale, with higher scores indicating that the company prioritizes product, service, technological, and process innovation.

\subsection{Data collection and Analysis Procedure}

Data was collected from marketing managers and SMEs in Nigeria during the month of July 2019. 400 questionnaires were distributed to participants, and 370 valid responses were obtained. Out of the 310 SMEs that participated in the study, 41.3 percent (128) have between 51 and 100 employees; 58.7 percent (182) have between 51 and 100 employees. In terms of employee counts, the SMEs profile reflects the Nigeran Small and Medium Enterprise Development agency of Nigeria (SMEDAN) SMEs classification. We examine the number of personnel working in Research and Development (R\&D) departments who have various educational certificates. We found that 52.5\% (163) of the SMEs that participated in the survey work in the service sector and 47.5 percent (147) work in the manufacturing industry. About 40.1\% (124) of personnel in (R\&D) departments have a bachelor's degree, 33.4 percent (104) have a higher degree, and 26.5 percent (82) have a diploma equivalent to an associate's degree. The educational level of employees in R\&D departments reveals that the sampled SMEs have a high intensity for product and process development in order to innovate. To begin, frequency analysis was used with SPSS (Bacon, 1997) to assess the demographic make-up of the responding SMEs and to assess the representativeness of the sampled SMEs. Second, confirmatory factor analysis was performed with AMOS to assess the theoretical structural of the factors under investigation, as well as the factors weights such as standardized factor loadings, t-statistics, goodness fit indices, convergent and divergent validity, and model reliability (Elreh). Third, we used Pearson correlation analysis to analyze the linear association between the variables, allowing us to predict the direction and type of the relationship between the variables. Fourth, numerous conditions must be met, including convergent and divergent validity, as well as model fit indices. The payoff now is to evaluate the independent variable's structural effects on the hypothesized mediator and the dependent variable, as well as the mediator variable's mediating properties.

\section{Data Analysis and Results}

\subsection{The Measurement Model}

The three constructs proposed model (see Fig. 2) achieved the appropriate model fit indices, as it recorded a chi-square of 1533.67 with degree of freedom 1102. GFI, CFI, NFI, TLI, and 


\section{Macrothink}

IFI were all above 0.9 and met the acceptable threshold of "Near 1" (Hair et al., 2015). RMSEA recorded for the measurement model was (0.051) well within the 'below 0.08 ' threshold of acceptance. RMR was 0.042, well within the 'below 0.06' threshold of acceptance, and finally the PCLOSE value recorded was 0.003 similarly within the accepted threshold of 'below 0.05 '.

Table 1 shows the CR values, which were all higher than the threshold. Similarly, the AVE coefficients explained by each construct exceeded the threshold of.50 Cronbach alpha coefficients, which also exceeded the threshold of .70.

Table 1. Validity and reliability of the questionnaire items

\begin{tabular}{llll}
\hline Construct & AVE & CR & $\alpha$ \\
\hline Market sensing & 0.795 & 0.932 & 0.920 \\
Knowledge creation & 0.716 & 0.966 & 0.951 \\
Innovation & 0.782 & 0.947 & 0.883 \\
\hline
\end{tabular}

Note. CR, construct reliability; AVE, average variance extracted; $\alpha$, Cronbach's alpha

\subsection{Test of the Model's Linearity}

This study used the Pearson correlation technique in SPSS to determine how closely the variables of interest co-vary. The standardized directions range from -1 (perfect negative correlation) to +1 (perfect positive correlation).

Table 3 demonstrates that market-sensing competence has a favorable relationship with knowledge creation process $(r=.944 ; .000)$ and product and process innovation $(r=.938 ; .000)$. Finally, the process of knowledge production shows a favorable relationship with product and process innovation $(\mathrm{r}=.966 ; .000)$. The mean scores were rather high, with market-sensing competence $(\mathrm{M}=3.910, \mathrm{~S} . \mathrm{D}=.871)$ coming in first, followed by knowledge creation process $(\mathrm{M}=3.881$, $\mathrm{S} . \mathrm{D}=.862)$ and product and process innovation $(\mathrm{M}=3.891, \mathrm{~S} . \mathrm{D}=.850)$.

Table 2. Inter-Construct correlations

\begin{tabular}{llllll}
\hline Construct & Mean & SD & 1 & 2 & 3 \\
\hline Market sensing & 3.910 & .871 & - & & \\
Knowledge creation & 3.881 & .862 & $.944^{* *}$ & - & \\
Innovation & 3.891 & .850 & $.938^{* *}$ & $.966^{* *}$ & - \\
\hline
\end{tabular}

\subsection{Testing the Hypotheses}

Table 3 and Figure 2 show the hypotheses that were tested. The results from SMEs are shown in Figure 2; the direct relationship between market-sensing competence and knowledge 


\section{Macrothink Institute ${ }^{\mathrm{TM}}$}

development process $(\beta=.52, \mathrm{p} .001)$ is positive and significant, supporting H1. In support of $\mathrm{H} 2$, the direct relationship between market-sensing capabilities and product and process innovation ( $\beta=.43$ p.001) is favorable and significant. Estimation results for the association between the knowledge creation process and product and process innovation reveal that the relationship is positive and significant ( $\beta=.67 \mathrm{p} .001$ ), supporting $\mathrm{H} 3$. The knowledge production process, according to Hypothesis 4, will mediate the relationship between market-sensing capability and product and process innovation. The authors use bias-corrected bootstrapping using a simulated sample $n=5,000$ and a 95 percent confidence interval to test the presence of mediation effect in the model, following the criteria laid out by the above-mentioned researchers. In this regard, the findings reveal that market-sensing capability has a favorable and considerable indirect effect on product and process innovation via the knowledge creation process $(\beta=.31 \mathrm{p} .01)$. The bias-corrected estimate suggested the following partial mediation: (95 percent confidence interval: .462 and .699). This finding gives credence to $\mathrm{H} 4$.

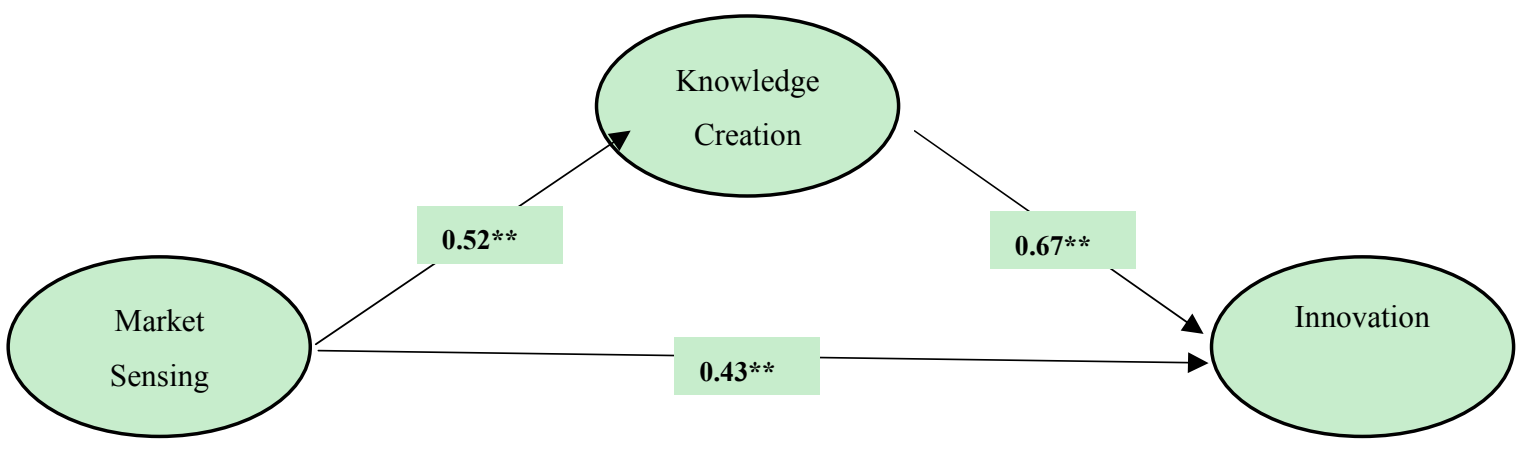

Figure 2. Hypothesized paths and effects

Table 3. Support for stated hypothesis

\begin{tabular}{lllll}
\hline & $\beta$ & $t$ & $p$ & \\
\hline Direct effects & & & & \\
\hline Market sensing -> Knowledge creation & 0.52 & 23.370 & .004 & $* * *$ \\
Market Sensing -> Innovation & 0.43 & 14.020 & .027 & $* * *$ \\
Knowledge creation --> Innovation & 0.67 & 31.331 & .018 & $* * *$ \\
\hline Indirect effects & & & & \\
\hline Market sensing --> knowledge creation --> Innovation & 0.31 & 11.022 & 0.29 & $* * *$ \\
\hline
\end{tabular}

\section{Discussion}

The interrelationships between market-sensing capacities, knowledge development processes, and product/process innovation in SMEs were studied in this study. Our investigation revealed that our research hypotheses were supported. The findings suggest that SMEs with strong market-sensing capacities can generate knowledge. This is in line with Ardyan's (2016) claim that when SMEs feel the market, their primary purpose is to hold knowledge of what 
their customers require and then use that knowledge to deliver relevant products and services based on the customer's requirements. According to the findings, SMEs with strong market-sensing capabilities are more inventive than those without. This finding is consistent with prior study (Calantone et al., 2002; Keskin, 2006), which found that the more an organization's ability to perceive the market, the better and more effective it is at being innovative. While it has been claimed that SMEs managers/owners do not fully know market sensing's fundamental notions (Ardyan, 2016), empirical research, including the outcomes of this study, has proven that SMEs managers/owners are capable of learning about the market. This is likely due to the fact that SMEs are closer to their customers, making it easier for them to comprehend their customers' clear and urgent demands, allowing them to create and offer services and products that are tailored to suit their desires. The process of knowledge generation was also found to have a significant positive relationship with product/process innovation in this study. Previous research has found that a firm's knowledge creation process influences its innovativeness (Binbin et al., 2012; Popadiuk \& Choo, 2006; Ramrez et al., 2011). Nonaka and Takeuchi (1995) emphasized the knowledge production process as a facilitator for a firm's innovativeness. The Arabian and SMEs context contributes to the uniqueness of our findings, as little has been done in this area. Furthermore, the inconsistency of the findings is a huge setback; nonetheless, researchers will gain more knowledge as a result of this outcome. The link between market-sensing capacities and product/process innovation was mediated by knowledge generation. Market sensing knowledge becomes a resource that SMEs may tap upon to ensure continual innovation. Lindblom et al. (2008) studied retail entrepreneurs and discovered that the capacity to feel the market and business performance, such as innovation, had a shaky link. They indicated that this could be due to the fact that other elements influencing the relationship between market sensing and performance, such as innovation, were not taken into account in their model/analysis, one of which could be the knowledge generation process. As a result, they confirmed the conclusions of this study, namely, that the knowledge creation process successfully mediates the relationship between SMEs' market-sensing capacities and their process and product innovation.

\section{Conclusion}

Using the hypotheses as a guide, it was discovered that market sensing is essential for active learning-positioning in SMEs. In addition, for company effectiveness, market sensing is combined with learning-positioning. Consumer, competitor, and, most importantly, market information influences how they investigate, pay attention to, and communicate the results for the innovative and overall function of knowledge. Furthermore, research reveals that SMEs' market sensing and learning procedures should be harmonized. The existence of a pressing need corresponded to these research paradigms that enable firms to run flawlessly. Due to the increased level of concern among researchers and specialists in an innovative firm, research efforts that include a market recognition planned invention will be highly valued. On the other hand, the findings provide practical support for the knowledge formation concept, the tendency to reconcile the relationship between market sensing abilities and novelty; it also exerts a straightening effect. 


\section{Recommendations for Future Research}

As with all empirical studies, there are certain limitations to this study. The findings may not be applicable to other countries with varying levels of national resources and structures. Furthermore, because the research methodology is cross-sectional, it limits and interferes with causal effects. Future studies should use multi-source data designs to support the current findings and reduce the effect of social desirability bias or common method bias. Exploring the impact of contextual elements around strategic entrepreneurial orientation in further depth can provide additional insights. Future studies should also concentrate on conducting a meta-analysis study, especially given the large number of quantitative studies that have accompanied throughout the domain of knowledge generation and innovation. Future meta-analysis studies should also look at the moderator effect, such as economic growth.

\section{References}

Aljarah, A., Emeagwali, L., Ibrahim, B., \& Ababneh, B. (2018). Does corporate social responsibility really increase customer relationship quality? A meta-analytic review. Social Responsibility Journal, SRJ-08-2018-0205.

Alrwashdeh, M., Emeagwali, O., \&amp; Aljuhmani, H. (2019). The effect of electronic word of mouth communication on purchase intention and brand image: An applicant smartphone brands in North Cyprus. Management Science Letters, 9(4), 505-518.

Andreou, P. C., Harris, T., \& Philip, D. (2017). Measuring Firms' Market Orientation Using Textual Analysis of 10-K Filings (December), 1-45.

Ardyan, E. (2016). Market sensing capability and SMEs performance: The mediating role of product innovativeness success. International Journal of Advanced and Applied Sciences, 2, 79-97.

Ayyagari, M., Beck, T., \& Demirguc-Kunt, A. (2007). Small and medium enterprises across the globe. Small Business Economics, 29, 415-434.

Ayyagari, M., Demirgüç-Kunt, A., \& Maksimovic, V. (2006). How well do institutional theories explain firms' perceptions of property rights?. The review of financial studies, 21(4), 1833-1871.

Bacon, L.D. (1997). Using Amos for Structural Equation Modeling in Market Research, SPSS, Chicago.

Ben-Menahem, S. M., von Krogh, G., Erden, Z., \& Schneider, A. (2016). Coordinating knowledge creation in multidisciplinary teams: Evidence from Early-Stage Drug Discovery. Academy of Management Journal, 59(4), 1308-1338.

Binbin, Z., Jiangstao, D., Mingxing, L., \& Tongjian, Z. (2012). The empirical research on independent technology innovation. Knowledge Transformation and Entreprise Growth RISUS, 3(2), 19-26. 


\section{Macrothink}

International Journal of Social Science Research

ISSN 2327-5510

2021, Vol. 9, No. 2

Calantone, R. J., Cavusgil, S. T., \& Zahao, Y. (2002). Learning orientation, firm innovation capability, and firm performance. Industrial Marketing Management, 31(6), 515-524.

Carson, D., Cromie, S., McGowan, P., \& Hill, J. (1995). Marketing and Entre-preneurship in SMEs: An Innovative Approach. London, UK: Prentice Hall.

Cladea. (2014). The Market Sensing Capability: Measure Development and Validation The Market Sensing Capability Concept: Measure Development and Validation Using Confirmatory Factor Analysis Introduction.

Cohen, W. M., \& Levinthal, D. A. (1990). Absorptive capacity: A new perspective on learning and innovation. Administrative Science Quaterly, 35(1), 128-152.

Day, G. S. (1994). The capabilities of market-driven organizations. Journal of Marketing, $58(4), 37$.

Donaldson, S. I., \& Grant-Vallone, E. J. (2002). Understanding self-report bias in organizational behavior research. Journal of Business Psychology, 17(2), 245-260.

Elrehail, H. (2018). The relationship among leadership, innovation and knowledge sharing: A guidance for analysis. Data in Brief, 19, 128-133.

Fang, S.-R., Chang, E., Ou, C.-C., \& Chou, C.-H. (2014). Internal market orientation, market capabilities and learning orientation. European Journal of Marketing, 48(1/2), 170-192.

Galunic, D. C., \& Rodan, S. (1998). Research Notes and Communications in the Firm: Resource Recombinations Knowledge Structures and the Potential for Schumpeterian. Strategic Management Journal, 19(12), 1193-1201.

Grant, R. M. (1996a). Prospering in dynamically-competitive environments: Organizational capability as knowledge integration. Organization Science, 7(4), 375-387.

Grant, R. M. (1996b). Toward a knowledge-based theory of the firm. Strategic Management Journal, 17(S2), 109-122.

Hallber, K. (2000). A Market-oriented Strategy for Small and Medium Scale Enterprises. Washington, D.C.

Jaworski, B. J., \& Kohli, A. K. (1993). Market Orientation: Antecedents and Consequences. Journal of Marketing, 57(3), 53.

Keskin, H. (2006). Market orientation, learning orientation, and innovation capabilities in SMEs: An extended model. European Journal of Innovation Management, 9(4), 396-417.

Lin, C. Y. (1998). Success factors of small and medium sized enterprises in Taiwan: an analysis of cases. Journal of Small Business Management, 36, 43-56.

Lindblom, A., Olkkonen, R., Kajalo, S., \& Mitronen, L. (2008). Market-sensing capability and business, performance of retail entrepreneurs. Contemporary Management Research, $4(3), 219-236$. 


\section{Macrothink}

International Journal of Social Science Research

ISSN 2327-5510

2021, Vol. 9, No. 2

Lukas, B. A., \& Ferrell, O. C. (2000). The effect of market orientation on product innovation. Journal of the Academy of Marketing Science; Spring, 28(2).

McKelvie, A., Wiklund, J., \& Brattström, A. (2018). Externally acquired or internally generated? Knowledge development and perceived environmental dynamism in new venture innovation. Entrepreneurship Theory and Practice, 42(1), 24-46.

Miller, D., \& Shamsie, J. (1996). The resource-based view of the firm in two environments: The hollywood film studios from 1936 to 1965. Academy of Management Journal, 39(3), 519-543.

Möller, K., \& Anttila, M. (1987). Marketing capability-A key success factor in small business?

Nonaka, I. (1994). A dynamic theory of organizational knowledge creation. Organization Science, 5(1), 14-37.

Nonaka, I., \& Takeuchi, H. (1995). The knowledge-creating company: How Japanese companies create the dynamics of innovation. Oxford university press.

Nonaka, I., \& von Krogh, G. (2009). Perspective-tacit knowledge and knowledge conversion: Controversy and advancement in organizational knowledge creation theory. Organization Science, 20(3), 635-652.

Nonaka, I., Von Krogh, G., \& Voelpel, S. (2006). Organizational knowledge creation theory: Evolutionary paths and future advances. Organization studies, 27(8), 1179-1208.

Perrewe, P. L., Hochwarter, W. A., Rossi, A. M., Wallace, A., Maignan, I., Castro, S. L., \& Van Deusen, C. A. (2002). Are work stress relationships universal? A nine-region examination of role stressors, general self-efficacy, and burnout. Journal of International Management, 8(2), 163-187.

Peschl, M. F., \& Fundneider, T. (2014). Designing and Enabling Spaces for collaborative knowledge creation and innovation: From managing to enabling innovation as socio-epistemological technology. Computers in Human Behavior, 37, 346-359.

Popadiuk, S., \& Choo, C. (2006). Innovation and Knowledge Creation: How are These Concepts Related? International Journal of Information Management, 26(4), 302-312.

Porter, M. E. (1986). Changing patterns of international competition. The International Executive, 28(2), 13-14.

Quintane, E., Mitch Casselman, R., Sebastian Reiche, B., \& Nylund, P. A. (2011). Innovation as a knowledge - based outcome. Journal of Knowledge Management, 15(6), 928-947.

Rakthin, S., Calantone, R. J., \& Wang, J. F. (2016). Managing market intelligence: The comparative role of absorptive capacity and market orientation. Journal of Business Research, 69(12), 5569-5577. 


\section{Macrothink}

International Journal of Social Science Research

ISSN 2327-5510

2021, Vol. 9, No. 2

Ramírez, A., Morales, V., \& Rojas, R. (2011). Knowledge Creation, Organizational Learning and their Effects on Organizational Performance. Engineering Economics, 22(3), 309-318.

Sankowska, A. (2013). Relationships between organizational trust, knowledge transfer, knowledge creation, and firm's innovativeness. The Learning Organization, 20(1), 85-100.

Shu, C., Page, A. L., Gao, S., \& Jiang, X. (2012). Managerial Ties and Firm Innovation: Is Knowledge Creation a Missing Link? Journal of Product Innovation Management, 29(1), $125-143$.

Škerlavaj, M., Song, J.H., Lee, Y. (2010). Organizational learning culture, innovative culture and innovations in South Korean firms. Expert Systems Applications, 37(9), 6390-6403.

Sołek-Borowska, C. (2017). Knowledge creation processes in small and medium enterprises: A Polish perspective. Online Journal of Applied Knowledge Management, 5(2), 61-75.

Teece, D. J. (2007). Explicating dynamic capabilities: The nature and micro-foundations of (sustainable) enterprise performance. Strategic Management Journal, 28(13), 1319-1350.

Teece, D. J. (2012). Dynamic capabilities: Routines versus entrepreneurial action. Journal of Management Studies, 49(8), 1395-1401.

Tsai, W. (2001). Knowledge transfer in intraorganizational networks: Effects of network position and absorptive capacity on business unit innovation and performance. Academy of Management Journal, 44(5), 996-1004.

Vorhies, D. W. (1998). An investigation of the factors leading to the development of marketing capabilities and organizational effectiveness. Journal of Strategic Marketing, 6(1), $3-23$.

\section{Copyrights}

Copyright for this article is retained by the author(s), with first publication rights granted to the journal.

This is an open-access article distributed under the terms and conditions of the Creative Commons Attribution license (http://creativecommons.org/licenses/by/4.0/). 